\title{
Perfil sanguíneo e peso de órgãos internos de bezerros leiteiros criados em diferentes sistemas de aleitamento ${ }^{1}$
}

\author{
Rafael A. Azevedo ${ }^{2 *}$, Ana Claudia M. Soares ${ }^{3}$, Sâmara R.A. Rufino², Gabriela A. \\ Bastos $^{3}$, Sandra G. Coelho ${ }^{2}$, Eduardo R. Duarte ${ }^{3}$ Luciana C. Geraseev $^{3}$ \\ e Neide J.F. Oliveira ${ }^{3}$
}

\begin{abstract}
Azevedo R.A., Soares A.C.M., Rufino S.R.A., Bastos G.A., Coelho S.G., Duarte E.R., Geraseev L.C. \& Oliveira N.J.F. 2014. [Blood profile and weight of internal organs of dairy calves in different nursing systems.] Perfil sanguíneo e peso de órgãos internos de bezerros leiteiros criados em diferentes sistemas de aleitamento. Pesquisa Veterinária Brasileira 34(8):785-790. Departamento de Zootecnia, Instituto de Ciências Agrárias, Universidade Federal de Minas Gerais, Avenida Universitária 1000, Montes Claros, MG 39404-547, Brazil. E-mail: rafaelzooufmg@gmail.com

The objective was to evaluate the blood profile together with the relative and absolute size of the internal organs of calves in conventional or fractionated feeding system. Ten females were used, with an average initial body weight of $37.53 \mathrm{~kg}( \pm 2.36)$, and 12 males with a mean body weight of $81.6 \mathrm{~kg}( \pm 8.6)$, both Holstein breed. The conventional feeding consisted of four liter milk supplied daily for 54 days of evaluation, and fractioned six liter milk was given from 6 to 25 days of age, four liter from 26 to 45 days of ager, and two liter from 46 to 59 days of age. Cynodon sp. hay, water and mineral supplement was provided $a d$ libitum. The experimental design was completely randomized with five replicates for blood parameters and six replicates for the development of internal organs. Blood collections were performed in females on days seven, 21, 28, 42, 49 and 56 of age. For the evaluation of internal organs males were slaughtered at two months of age, after 16 hours of fasting. No differences occurred in the values of total protein, albumin, globulin, creatinine, urea, cholesterol and $\beta$-hydroxybutyrate in ages evaluated ( $p>0.05)$. However, for the concentration of glucose no interaction was found between lactation systems and periods evaluated. It can be noted that at 21 days of age the concentration was higher in calves kept in the fractionated system, when compared with animals of the conventional group. The feeding system did not affect the final body weight, the empty body weight or the weight of the internal organs, except for the heart, demonstrating that the fractional feeding system does not alter the assessment of the internal organs.
\end{abstract}

INDEX TERMS: Nursing systems, carcass yield, fat, heart, metabolites, milk, ruminants.

RESUMO.- Objetivou-se avaliar o perfil sanguíneo e o tamanho absoluto e relativo dos órgãos internos de bezerros em sistema de aleitamento convencional ou fracionado. Foram utilizadas 10 fêmeas, com peso corporal inicial médio de $37,53 \mathrm{~kg}( \pm 2,36)$ e 12 machos com peso corporal médio

\footnotetext{
${ }^{1}$ Recebido em 12 de dezembro de 2013.

Aceito para publicação em 4 de julho de 2014.

${ }^{2}$ Departamento de Zootecnia, Instituto de Ciências Agrárias da Universidade Federal de Minas Gerais, Av. Universitária 1000, Montes Claros, MG 39404-547, Brasil. *Autor para correspondência: rafaelzooufmg@gmail.com

${ }^{3}$ Departamento de Zootecnia, Instituto de Ciências Agrárias, UFMG, Avenida Universitária 1000, Montes Claros, MG 39404-547, Brasil.
}

de $81,6 \mathrm{~kg}( \pm 8,6)$, ambos da raça Holandesa. 0 aleitamento convencional constituiu-se de quatro litros de leite fornecidos diariamente durante 54 dias de avaliação e o fracionado, de seis litros do 6o ao $25^{\circ}$ dias de idade, quatro litros do $26^{\circ}$ ao $45^{\circ}$ dias de idade e dois litros do $46^{\circ}$ ao $59^{\circ}$ dias de idade, além de concentrado, feno de Cynodon sp., água e suplemento mineral fornecidos ad libitum. $\mathrm{O}$ delineamento experimental foi inteiramente ao acaso, com cinco repetições para os parâmetros sanguíneos e seis repetições para o desenvolvimento dos órgãos internos. As coletas de sangue foram realizadas nas fêmeas nos dias sete, $21,28,42$, 49 e 56 de idade. Para a avaliação dos órgãos internos os 
machos foram abatidos aos dois meses de idade, após jejum de 16 horas. Não foram observadas diferenças para os valores de proteínas totais, albumina, globulina, creatinina, ureia, colesterol e $\beta$-hidroxibutirato nas idades avaliadas $(p>0,05)$. Entretanto, para a concentração de glicose houve interação entre os sistemas de aleitamento e os períodos avaliados, podendo ser observado que com 21 dias de idade a concentração foi maior nas bezerras mantidas em sistema fracionado, quando comparadas aos animais do grupo convencional. 0 sistema de aleitamento não alterou o peso corporal final, peso corporal final vazio e o peso dos órgãos internos, exceto para o coração, demonstrando que o sistema de aleitamento fracionado não altera as avaliações dos órgãos internos.

TERMOS DE INDEXAÇÃO: Sistemas de aleitamento, coração, leite, gordura, metabólitos, rendimento de carcaça, ruminantes.

\section{INTRODUÇÃO}

0 aleitamento convencional de bezerros leiteiros é caracterizado pelo fornecimento da dieta líquida em quantidade constante, equivalente a $10 \%$ do peso corporal do animal, dividido em duas refeições diárias (Azevedo et al. 2013). Esse sistema, entretanto, atende pouco mais que as exigências de mantença dos animais (Van Amburgh \& Drackley 2005), proporcionando baixo ganho de peso e pouca eficiência alimentar (Davis \& Drackley 1998, Khan et al. 2007), além de comportamentos sugestivos de fome (Thomas et al. 2001).

0 sistema de aleitamento fracionado tem sido estudado e caracteriza-se pelo fornecimento da dieta líquida em quantidades superiores ao sistema convencional, seguido de reduções posteriores, com o objetivo de estimular o consumo de alimentos sólidos pelos animais (Sweeney et al. 2010). Dessa forma, ocorre melhoria do estado nutricional no período inicial de vida dos animais, minimizando o estresse, pois a mudança da dieta acontece de forma gradativa e os animais passariam a ingerir maior quantidade de concentrado (Hill et al. 2006, Hill et al. 2007, Azevedo et al. 2014a).

Adotar o aleitamento fracionado, com restrições gradativas até a desmama, pode permitir que os bezerros recebam quantidades de leite mais próximas as condições em que os bezerros teriam acesso ad libitum ao leite (Stamey et al. 2005), sendo esperado aumento linear do consumo de sólidos, proporcionalmente à diminuição gradual na ingestão liquida, influenciando o desenvolvimento dos animais, pois a nutrição pode modificar as taxas de crescimento dos animais (Velayudhan et al. 2008), proporcionando, possivelmente, alterações dos metabólitos sanguíneos e do desenvolvimento dos órgãos internos.

Os principais componentes bioquímicos sanguíneos representativos do metabolismo energético são os valores séricos de glicose, de colesterol e de $\beta$-hidroxibutirato. Em contrapartida, para a análise do metabolismo proteico, avalia-se proteínas totais, albumina, globulina, ureia e creatinina, (Dirksen \& Breitner 1993), e estudos dos parâmetros sanguíneos, relacionando à estratégia de aleitamento sobre o desempenho de bezerras leiteiras podem ser fundamen- tais para a escolha do sistema adequado a ser adotado nas propriedades leiteiras.

Por não participar da composição da carcaça, existem poucos estudos sobre o desenvolvimento esplâncnico de bovinos, e essas variáveis podem influenciar diretamente o rendimento comercial (Carvalho et al. 2003), além de estarem associadas às diferenças nas exigências nutricionais de mantença dos animais (Rocha 1997), o que pode relacionar-se com o melhor e correto desenvolvimento futuro dos mesmos, pois, segundo Johnson et al. (1990), a compreensão do desenvolvimento do tecido esplâncnico pode fornecer métodos para possivelmente avaliar a composição da produção animal.

Objetivou-se avaliar os parâmetros sanguíneos e o peso dos órgãos internos de bezerros leiteiros da raça Holandesa criados em sistema de aleitamento convencional ou fracionado.

\section{MATERIAL E MÉTODOS}

O experimento foi conduzido no setor de Nutrição de Ruminantes do Instituto de Ciências Agrárias da Universidade Federal de Minas Gerais (ICA/UFMG), Montes Claros, Minas Gerais, Brasil. O experimento foi previamente aprovado pelo comitê local de ética em experimentação animal CETEA, sob o protocolo número 39/2009 e $178 / 11$.

Os animais, cinco fêmeas e seis machos/tratamento, todos provenientes da Fazenda Experimental Professor Hamilton Navarro do ICA/UFMG, foram criados em baias individuais $(1,20 \mathrm{~m}$ de largura, $2 \mathrm{~m}$ de comprimento e 1,30 $\mathrm{m}$ de altura) com pisos cobertos por areia, equipadas com baldes para fornecimento de água, concentrado, feno e suplemento mineral. Os tratamentos foram compostos por aleitamento convencional, com quatro litros de leite diários, e fracionado, respectivamente com seis, quatro e dois litros de leite diários do $6^{\circ}$ a a $25^{\circ}$, do $26^{\circ}$ ao $45^{\circ}$ e e do $46^{\circ}$ ao 59 ias de vida. Forneceram-se ambos os tratamentos em duas refeições, de quantidades equivalentes a $50 \%$ do total, às $8 \mathrm{~h}$ e às $16 \mathrm{~h}$, em mamadeiras com capacidade para dois litros.

Todo o manejo pré-experimental e a composição bromatológica do leite, concentrado e do feno utilizados foram descritos por Azevedo et al. (2013).

Amostras de sangue foram coletadas nas fêmeas nos dias sete, $21,28,42,49$ e 56 do experimento. As colheitas foram realizadas antes do aleitamento da manhã com a punção da veia jugular externa e garroteamento manual do vaso, utilizando-se tubos contendo vácuo. Em seguida, o material foi centrifugado a 1500 rpm durante 15 min para separação do plasma e do soro. Após centrifugação, plasma e soro foram armazenados em tubos eppendorf até a análise química em laboratório. As concentrações dos parâmetros avaliados foram determinadas utilizando-se kits enzimáticos. As concentrações de proteínas totais, albumina, creatinina, ureia, glicose, colesterol foram mensuradas a partir de kits enzimático colorimétrico e cinético comerciais (Bioclin-QUIBASA Química Básica Ltda., Belo Horizonte, MG, Brasil). A metodologia adotada foi realizada segundo a determinação indicada pelo fabricante. Para a leitura das concentrações foi utilizado aparelho de espectrofotometria em Sistema Automático para Bioquímica - Modelo NOVA 1600/1800UV. A determinação de $\beta$-hidroxibutirato (BHBA) foi realizada utilizando-se kit enzimático cinético RANBUT - Ref.: RB 1007 (RANDOX Laboratories - Life Sciences Ltd, Crumlin, UK), por espectrofotometria em Sistema Automático para Bioquímica-Modelo BIOPLUS BIO 2000. Os valores de globulinas séricas foram obtidos por meio da diferença entre as concentrações de proteínas totais e albumina. 
Aos 59 dias de idade, todos os machos foram pesados individualmente para obtenção do peso corporal final (PCF). Ao completarem 60 dias de idade, os animais foram pesados novamente, individualmente, após jejum alimentício de 16 h, com livre acesso a água, para a obtenção do peso corporal final após o jejum (PCFJ). Para eutanásia administrou-se medicação pré-anestésica (Cloridrato de xilazina a $2 \%$, Roumpun ${ }^{\circledR}-1,5 \mathrm{mg} / \mathrm{kg}$ de peso corporal) e anestésica geral (Pentorbabital sódico Tiopental ${ }^{\circledR}, 10 \mathrm{mg} / \mathrm{kg}$ de peso corporal), seguida por sangria jugular.

Imediatamente após o abate e abertura da cavidade abdominal, procedeu-se à ligadura da porção caudal do esôfago com o cárdia, da cranial do duodeno com o esfíncter pilórico, do orifício retículo omasal assim como também do orifício omaso-abomasal. 0 trato gastrintestinal cheio foi removido e pesado, e posteriormente esvaziado e lavado, sendo novamente pesado, obtendo-se assim o seu peso vazio.

Deduzindo-se o peso do trato gastrintestinal cheio do seu peso vazio, obtinha-se o peso do conteúdo do trato gastrintestinal, que, subtraindo-se do peso corporal final após o jejum, além do conteúdo presente na vesícula biliar e na bexiga, obteve-se o peso corporal vazio (PCVZ) de cada animal. Os pesos dos órgãos internos foram avaliados de forma absoluta e relativa ao peso corporal final vazio (\% PCVZ).

Os animais foram distribuídos em delineamento inteiramente ao acaso, com dois tratamentos, convencional e fracionado.

Os parâmetros sanguíneos das fêmeas foram analisados em subparcelas (dois sistemas e seis períodos) sendo as médias das variáveis qualitativas (dietas de aleitamento) comparadas pelo teste de Student Newman Keuls, e as médias das variáveis quantitativas (períodos) submetidas à análise de regressão quando necessário. As análises foram feitas utilizando-se o programa SAEG (Sistema para análises estatísticas e genéticas).

Os dados de órgãos e vísceras foram submetidos à análise de variância e a teste de comparação de médias, sendo os efeitos comparados pelo teste de Tukey, a $5 \%$ de probabilidade, com auxílio do programa SAS (SAS Institute 2002) pelo procedimento GLM.

Valores de probabilidade abaixo de 0,05 foram considerados como significativos e acima de 0,05 mas abaixo de 0,10 como tendência.

\section{RESULTADOS}

O sistema de aleitamento não alterou os parâmetros sanguíneos nos dias sete, 28, 42, 49 e 56 (p>0,05), entretanto, aos 21 dias de idade, o sistema fracionado proporcionou concentrações de glicose superiores aos animais em aleitamento convencional (Quadro 1).

Foram observados crescimento lineares $(\mathrm{p} \leq 0,05)$ nas concentrações dos parâmetros em função dos períodos para as concentrações de proteína total, albumina, globulina, colesterol e ureia em função do período avaliado, sendo observadas concentrações de proteína total decrescentes ao longo dos períodos para ambos os sistemas, com a seguinte equação de regressão linear $\mathrm{y}=-0,1978 \mathrm{x}$ período de avaliação + 6,8891 e R $\mathrm{R}^{2}$ 0,2549.

As concentrações de globulina, colesterol e $\beta$-hidroxibutirato ( $\mathrm{mmol} / \mathrm{L})$ também foram decrescentes ao longo dos períodos para ambos os sistemas. Já as concentrações de albumina sérica apresentaram equação de regressão linear crescente de $\mathrm{y}=0,0106 \mathrm{x}$ período de avaliação + 2,5136 e $\mathrm{R}^{2} 0,20$.

0 peso corporal final ao desaleitamento dos bezerros machos apresentou tendência de superioridade para os animais tratados de forma fracionada $(p=0,08)$, sendo esses 7,0 \% mais pesados quando comparados aos bezerros mantidos no sistema convencional (Quadro 2).

As avaliações dos órgãos internos revelaram efeito $(\mathrm{p} \leq 0,05)$ do sistema de aleitamento somente para peso absoluto e relativo do coração (Quadro 3), o qual foi superior em 7,3\% ( $\mathrm{p} \leq 0,05)$ nos animais no aleitamento fracionado em comparação ao sistema convencional. 0 peso relativo de baço apresentou tendência $(\mathrm{p}=0,07)$ de superioridade para os animais em aleitamento fracionado. Os possíveis maiores $(\mathrm{p} \leq 0,05)$ consumos de alimentos sólidos no terceiro período de avaliação observados para os animais em aleitamento fracionado (Azevedo et al. 2013) não alteraram o desenvolvimento da maioria dos órgãos internos.

Quadro 1. Médias em gramas por decilitro $(\mathrm{g} / \mathrm{dL})$ de proteína total (PT), de albumina (ALBU), de globulina (GLOBU) em miligramas por decilitro (mg/dL), de creatinina (CREAT), de colesterol (COLE), ureia (UREI) no soro e em milimol por litro (mmol/L) de $\beta$-hidroxibutirato (B-HI) no plasma sanguíneo de bezerras Holandesas criadas em dois sistemas de aleitamento até 59 dias de idade

\begin{tabular}{|c|c|c|c|c|c|c|c|}
\hline Tratamento & $\mathrm{PT}$ & ALBU & GLOBU & CREAT & COLE & UREI & B-HI \\
\hline Convencional & 6,39 & 2,86 & 3,53 & 1,34 & 101,85 & 14,53 & 1,00 \\
\hline Fracionado & 6,00 & 2,91 & 3,09 & 1,27 & 99,13 & 15,33 & 0,97 \\
\hline $\mathrm{CV}$ & 7,72 & 11,87 & 19,14 & 22,60 & 12,71 & 24,05 & 19,64 \\
\hline \multicolumn{8}{|c|}{ Interações } \\
\hline \multirow{2}{*}{ Sistema } & 7 & 21 & 28 & 42 & 49 & 56 & \\
\hline & \multicolumn{6}{|c|}{ Glicose } & \\
\hline Convencional & $\begin{array}{l}3,39^{\mathrm{aA}} \\
167^{\mathrm{aA}}\end{array}$ & $\begin{array}{r}92, \\
127\end{array}$ & $\begin{array}{r}97,83 \\
9 B \quad 9681\end{array}$ & $\begin{array}{r}91,01 \\
107,55\end{array}$ & 108, & $97,88^{a}$ & \\
\hline
\end{tabular}

Médias seguidas de mesma letra minúscula na coluna, dentro de cada fator, não diferem entre si; Médias seguidas por letras maiúsculas iguais na linha não diferem entre si. CV = Coeficiente de variação.

Quadro 2. Médias de peso corporal final (PCF) e peso corporal final vazio (PCVZ) de bezerros holandeses criados em diferentes sistemas de aleitamento artificial até 60 dias de idade

\begin{tabular}{lcccc}
\hline Parâmetros & Convencional & Fracionado & EPM $^{\mathrm{a}}$ & $P$ \\
\hline PCF (Kg) & 79,5 & 84,0 & 2,50 & 0,08 \\
PCVZ (Kg) & 71,0 & 75,0 & 2,08 & 0,29
\end{tabular}

${ }^{\mathrm{a}} \mathrm{EPM}$ = Erro padrão da média. As médias de PCF e PCVZ foram ajustadas para a covariável peso ao nascimento $(\mathrm{p} \leq 0,05)$.

\section{DISCUSSÃO}

Os valores encontrados para os parâmetros sanguíneos dos animais estão de acordo com os da literatura para animais recebendo aleitamento convencional ou fracionado (Shingu et al. 2007, Blome et al. 2003) e resultados semelhantes foram descritos por Lima et al. (2012) ao avaliarem os parâmetros séricos de bezerros submetidos a diferentes dietas líquidas.

A concentração de albumina no soro dos animais pode variar em função da quantidade de proteína ingerida na dieta. Portanto, baixas concentrações séricas podem ser indicador de déficit proteico na alimentação do animal (Reis 
Quadro 3. Médias de peso absoluto (g) e relativos, em \% do peso corporal vazio (PCVZ), dos órgãos e gordura interna de bezerros holandeses mantidos em diferentes sistemas de aleitamento artificial até os 60 dias de idade

\begin{tabular}{lcccc}
\hline Parâmetro & Convencional & Fracionado & EPM $^{\mathrm{a}}$ & $P$ \\
\hline Fígado (g) & 1580,66 & 1626,83 & 67,88 & 0,75 \\
Fígado (\% PCVZ) & 2,27 & 2,12 & 0,08 & 0,38 \\
Pulmão (g) & 814,00 & 885,66 & 24,98 & 0,16 \\
Pulmão (\% PCVZ) & 1,17 & 1,15 & 0,02 & 0,70 \\
Baço (g) & 435,66 & 251,66 & 56,67 & 0,10 \\
Baço (\% PCVZ) & 0,63 & 0,32 & 0,08 & 0,07 \\
Coração (g) & $455,52^{\mathrm{b}}$ & $510,47^{\mathrm{a}}$ & 17,48 & 0,01 \\
Coração (\% PCVZ) & 0,63 b & $0,68{ }^{\text {a }}$ & 0,01 & 0,01 \\
Rins (g) & 326,66 & 377,00 & 21,46 & 0,25 \\
Rins (\% PCVZ) & 0,46 & 0,47 & 0,03 & 0,65 \\
Pâncreas (g) & 71,00 & 77,66 & 5,18 & 0,62 \\
Pâncreas (\% PCVZ) & 0,10 & 0,10 & 0,01 & 0,86 \\
Gordura omental (g) & 330,33 & 296,50 & 30,57 & 0,60 \\
Gordura omental (\% PCVZ) & 0,46 & 0,37 & 0,04 & 0,31 \\
Mesentério mais gordura (g) & 431,33 & 437,00 & 51,46 & 0,95 \\
Mesentério mais gordura (\% PCVZ) & 0,61 & 0,55 & 0,06 & 0,54
\end{tabular}

${ }^{a}$ EPM = Erro padrão da média. Médias seguidas de letra diferentes na linha, dentro de cada fator, se diferem estatisticamente entre si. As médias de coração (g) foram ajustadas para a covariável peso ao nascimento $(\mathrm{p} \leq 0,05)$.

et al. 2007), o que não ocorreu no presente trabalho, pois as concentrações séricas de albumina foram crescentes em função dos períodos avaliados para ambos os sistemas.

As concentrações séricas de globulina e albumina são inversamente proporcionais, para manter o equilíbrio osmótico do sangue (Payne \& Payne 1987), justificando-se os resultados com concentrações de albumina crescentes e concentrações de globulina decrescentes nos períodos avaliados, e, segundo Kaneko et al. (2008), os valores altos de proteínas totais logo após o nascimento ocorrem em virtude da ingestão do colostro e com isso apresenta baixos valores de globulina sérica.

Causas patológicas para o aumento de ureia em função dos períodos de avaliação foram descartadas, pois o metabolismo de proteínas totais, albumina e globulinas dependente do fígado, indicam que estavam em concentrações normais, além da similaridade de tamanho desse órgão entre os animais de ambos os tratamentos (Quadro 2). Também não foram observados sinais de doença renal nos animais experimentais, excluindo causas de aumento da ureia relacionadas a lesões no sistema excretor.

Os valores de creatinina encontrados são próximos aos descritos por Lima et al. (2012) em bezerros submetidos a diferentes tipos de dietas líquidas e foram similares, as médias encontram-se dentro do limite de normalidade (1 a $2 \mathrm{mg} / \mathrm{dL}$ ) para bovinos (Reece 2006).

As concentrações de $\beta$-hidroxibutirato tendem a aumentar com a idade, pois o consumo de dieta sólida aumenta e consequentemente inicia-se o metabolismo ruminal com produção de corpos cetônicos (Quigley et al. 1991). Entretanto, no presente trabalho, verificou-se resultados contrários, pois os valores decresceram ao longo dos períodos, fato justificado pela faixa etária dos animais, pois os corpos cetônicos são produzidos para atender a demanda energética de outros órgãos que ainda não são capazes de gerar a própria energia. Ou seja, os animais apresenta- ram glicemia dentro da normalidade, fazendo com que não ocorre-se a necessidade de utilização dos corpos cetônicos como fonte de energia.

As concentrações de $\beta$-hidroxibutirato são menores durante o aleitamento e a elevação dessas só ocorre com o aumento significativo na quantidade de concentrado na dieta, após o desaleitamento, quando os animais passam a absorver quantidades consideráveis de ácidos graxos de cadeia curta (AGCC) e os utilizam como fonte de energia (De Paula, 2012).

Estudos realizados por Kristensen et al. (2007), fornecendo diferentes quantidades de dieta líquida, mostraram que bovinos em aleitamento fracionado apresentaram menores concentrações plasmáticas de $\beta$-hidroxibutirato em relação aos do tratamento convencional. Segundo os autores os bezerros do aleitamento convencional consumiram concentrado mais precocemente e os produtos da fermentação contribuíram como fonte de energia para o metabolismo animal. Entretanto, segundo Azevedo et al. (2014a), foi observada diferença significativa para o consumo de concentrado entre ambos os tratamentos somente no último período de aleitamento, com superioridade para os animais em sistema fracionado.

Verificou-se que ambos os tratamentos tiveram concentrações baixas e decrescentes de $\beta$-hidroxibutirato com a idade, fato que pode ser justificado pelas concentrações de glicose circulante dentro do padrão de normalidade. De Paula (2012) observou diferença entre tratamentos intensivo e convencional, com efeito do avanço da idade, pois com o tempo ocorre o desenvolvimento do rúmen e esse período pode influenciar em algumas variáveis sanguíneas. Resultados semelhantes foram encontrados por Haga et al. (2008) trabalhando com bezerros da raça Holandesa recebendo sucedâneos com 25,5\% proteína bruta e 21,4\% extrato etéreo.

Segundo Terré et al. (2006), maiores concentração de glicose em animais recebendo aleitamento intensivo associado ao maior consumo de dieta líquida são esperados. Os resultados de glicose verificados corroboram com esses autores, pois a avaliação aos 21 dias de idade, período onde os animais que estavam em aleitamento fracionado recebiam maiores volumes de leite quando comparados aos animais em sistema convencional, demonstrou maiores concentrações de glicose. Da mesma forma, Khan et al. (2007) observaram animais em aleitamento intensivo com concentrações de glicose superiores aos mantidos em aleitamento convencional. Já Silper et al. (2014) não verificaram diferenças entre os teores de glicose sanguínea entre animais em sistema intensivo, fracionado ou convencional de aleitamento.

De Paula (2012) ao avaliar bezerros leiteiros em programas de aleitamento intensivo ou convencional, não verificou diferença significativa entre os tratamentos para as concentrações plasmáticas de glicose. Os valores observados se assemelham aos encontrados para animais nesse período de vida recebendo aleitamento convencional e intensivo (Blome et al. 2003, Shingu et al. 2007).

0 peso de bezerros aos 60 dias de vida deve corresponder ao dobro do peso ao nascimento (Soberon et al. 2012). 
No presente trabalho essa meta foi atingida em ambos os grupos, sendo verificados valores superiores ao dobro do peso inicial em 6,0 e 9,5 kg, respectivamente para o aleitamento convencional e fracionado.

Os consumos de concentrado, feno e matéria seca total e o desenvolvimento intestinal dos animais são discutidos em detalhe por Azevedo et al. (2013).

Apesar da tendência de diferença no peso final dos animais, o peso corporal final vazio foi similar entre os tratamentos, possivelmente, podendo ser relacionado ao maior enchimento do trato gastrointestinal nos bezerros alimentados no sistema fracionado (Azevedo et al. 2013) e a menor ingestão de leite no período final do experimento.

Lima (2008), ao avaliar a influência de diferentes dietas líquidas sobre o peso de órgãos viscerais de bezerros Holandeses aos 60 dias de idade, não verificou efeitos dos tratamentos para as variáveis analisadas. Já Azevedo et al. (2014b), verificaram que o fornecimento de um substituto lácteo comprometeu o desempenho corporal final dos bezerros e resultou em menores pesos dos órgãos internos e de gordura interna.

Os órgãos internos apresentam elevadas taxas metabólicas e, principalmente, o fígado tende a responder por alterações na ingestão de alimentos (Ferrell \& Jenkins 1998), o que não foi observado na presente pesquisa, pois o fígado, órgão que tende a responder com aumentos de peso em dietas com maior densidade energética (Owens et al. 1993), apresentou peso similar entre os sistemas ( $p>0,05)$, possivelmente pelo fato dos animais terem sido alimentados com dietas com concentrações energéticas similares, embora em sistemas diferentes.

Ribeiro et al. (2001), ao avaliarem o tamanho de órgãos viscerais de bezerros Holandeses para produção de vitelos, observaram que, à medida que se aumentaram as quantidades de concentrado nas dietas, os pesos absolutos do fígado, rins, pulmões, mesentério e gordura presentes nas carcaças aumentaram linearmente, sendo observado efeito quadrático para coração e efeito linear crescente para rins, fígado e pulmões.

Como o peso corporal final foi similar entre os animais de ambos os sistemas (Quadro 3), não foi encontrada uma explicação plausível para o maior peso do coração no grupo fracionado.

Em animais alimentados com planos nutricionais baixos, mesmo que por longo período de tempo, o coração e o pulmão tendem manter a sua integridade, demonstrando prioridade na utilização dos nutrientes (Lima 2008). Ferreira et al. (2000) relataram que, independentemente do plano nutricional, os pesos absolutos do coração e dos pulmões dificilmente são influenciados. Melo et al. (2007) constaram que o peso absoluto do coração não foi diferente nos sistemas com ou sem restrição alimentar para bezerros leiteiros, diferentemente do observado para o peso absoluto dos pulmões.

Segundo Solis et al. (1988), maiores proporções de gordura visceral em animais de aptidão leiteira resultariam, na prática, em maiores exigências de energia para mantença, em virtude da maior atividade metabólica do tecido adiposo interno em relação ao tecido adiposo periférico.

\section{CONCLUSÃo}

$\mathrm{O}$ aleitamento convencional e fracionado não alteraram as concentrações de metabólitos sanguíneos de bezerras holandesas, com exceção das concentrações de glicose, a qual foi superior nos animais durante o fracionamento aos 21 dias de idade, e também não influenciaram o peso dos órgãos viscerais dos bezerros, sendo que somente o coração apresentou diferença de massa absoluta entre os sistemas.

Agradecimentos.- À empresa TECNUTRI pelo patrocínio, ao Conselho Nacional de Desenvolvimento da Pesquisa (CNPq) e à Fundação de Amparo a Pesquisa do Estado de Minas Gerais (FAPEMIG) pelo apoio financeiro e pelas bolsas de iniciação científica e de pós-graduação.

\section{REFERÊNCIAS}

Azevedo R.A., Araújo L., Duarte D.V.L., Cruz M.S., Costa S.F., Oliveira N.J.F., Duarte E.R. \& Geraseev L.C. 2013. Desenvolvimento do trato digestivo de bezerros leiteiros. Pesq. Vet. Bras. 33:931-936.

Azevedo R.A., Rufino S.R.A., Duarte D.V.L., Soares A.C.M. \& Geraseev L.C. 2014a. Desempenho de bezerros leiteiros em aleitamento artificial convencional ou fracionado. Revta Bras. Saúde Prod. Anim. 15:237-247.

Azevedo R.A., Duarte D.V.L., Soares A.C.M., Oliveira N.J.F., Coelho S.G., Duarte E.R. \& Geraseev L.C. 2014b. Desenvolvimento de bezerros leiteiros alimentados com silagem de leite de transição. II - Órgãos internos. Arq. Bras. Med. Vet. Zootec. 66:505-509.

Blome R.M., Drackley J.K., Mckeith F.K., Hutiens M.F. \& Mccoy G.C. 2003. Growth, nutrient intake, and body composition of dairy calves fed milk replacers containing different amounts of protein. J. Anim. Sci. 81:16411655.

Carvalho P.A., Sanchez L.M.B. \& Viégas J. 2003. Desenvolvimento de estômago de bezerros holandeses desaleitados precocemente. Revta Bras. Zootec. 32:1461-1468.

Davis C.L. \& Drackley J.K. 1998. The Development, Nutrition, and Management of Young Calf. Iowa State University Press, Ames. 339p.

De Paula. 2012. Alterações no metabolismo energético e no desempenho de bezerros leiteiros em programas de aleitamento intensivo ou convencional. Dissertação de Mestrado em Ciências, Escola Superior de Agricultura "Luiz de Queiroz", Universidade Estadual de São Paulo, Piracicaba, SP. 82p.

Dirksen G. \& Breitner W. 1993. New quick-test for semi quantitative determinations of beta-hydroxybutyric acid in bovine milk. J. Vet. Med. Anim. Physiol. Patol. Clin. Med. 40:779-784.

Ferrell C.L. \& Jenkins T.G. 1998. Body composition and energy utilization by steers of diverse genotypes fed a high concentrate diet during the finishing period: Angus, Boran, Brahman, Hereford, and Tuli Sires. J. Anim. Sci. 76:647-657.

Ferreira M.D.A., Valadares Filho S.D.C., Muniz E.B. \& Veras A.S.C. 2000. Características das carcaças, biometria do trato gastrintestinal, tamanho dos órgãos internos e conteúdo gastrintestinal de bovinos F1 Simental x Nelore alimentados com dietas contendo vários níveis de concentrado. Revta Bras. Zootec. 29:1174-1182.

Haga S., Fujimoto S., Yonezawat T., Yoshioka K., Shingu H., Kobayashi Y., Takahashi T., Otani Y., Katoh K. \& Obara Y. 2008. Changes in hepatic key enzymes of dairy calves in early weaning production systems. J. Dairy Sci. 91:3156-3164.

Hill T.M., Aldrich J.M., Schlotterbeck R.L. \& Bateman II H.G. 2006. Effects of feeding rate and concentrations of protein and fat of milk replacers fed to neonatal calves. Prof. Anim. Scient. 22:374-381.

Hill T.M., Aldrich J.M., Schlotterbeck R.L. \& Bateman II H.G. 2007. Effects of changing the fat and fatty acid composition of milk replacers fed to neonatal calves. Prof. Anim. Sci. 23:135-143.

Johnson D.E., Johnson K.A. \& Baldwin R.L. 1990. Changes in liver and gastrointestinal tract energy demands in response to physiological workload in ruminants. J. Nutri., 120, 649-655. 
Kaneko J.J., Harvey J.W. \& Bruss M.L. 2008. Clinical Biochemistry of Domestic Animal. $6^{\text {th }}$ ed. Academic Press, San Diego. 918p. (Apud Moraes 2011)

Khan M.A., Lee H.J., Lee W.S., Kim H.S., Kim S.B., Ki K.S., Ha J.K. Lee H.G. \& Choi Y.J. 2007. Pre- and postweaning performance of Holstein female calves fed milk through step down and conventional methods. J. Dairy Sci. 90:876-885.

Kristensen N.B., Sehested J., Jensen S.K. \& Vestergaard M. 2007. Effect of milk allowance on concentrate intake, ruminal environment and ruminal development in milk-fed Holstein calves. J. Dairy Sci. 90:4346-4355.

Lima P.O. 2008. Substituição parcial do leite por soro de queijo e ovo na dieta líquida de bezerros leiteiros. Tese de Doutorado em Zootecnia, Universidade Federal do Ceará, Fortaleza, CE. 123p.

Lima P.O., Cândido M.J.D., Queiroz M.G.R., Ferreira J.M., Modesto E.C., Lima R.N., Gomes J.M.C. \& Aquino R.M.S. 2012. Parâmetros séricos de bezerros submetidos a diferentes tipos de dietas líquidas. Revta Bras. Saúde Prod. Anim. 13:529-540.

Melo W.S., Véras A.S.C. \& Ferreria M.A. 2007. Cortes nobres, componentes do peso vivo e órgãos viscerais de bovinos mestiços de origem leiteira em condições de pastejo, restrito ou "ad libitum". Revta Bras. Ciênc. Agrárias 2:90-97.

Moraes D.V. 2011. Perfil bioquímico sérico de bezerros mestiços durante o primeiro ano de vida. Dissertação de Mestrado em Ciências Veterinárias, área de concentração em Saúde Animal, Faculdade de Medicina Veterinária, Universidade Federal de Uberlândia, Uberlândia, MG. 40p.

Owens F.N., Dubeski P. \& Hanson C.F. 1993. Factors that alter the growth and development of ruminants. J. Anim. Sci. 71:3138-3150.

Payne J.M. \& Payne S. 1987. The metabolic profile test. Oxford University Press, Oxford. (Apud Peixoto \& Osório 2007)

Peixoto L.A.O. \& Osório M.T.M. 2007. Perfil metabólico proteico e energético na avaliação do desempenho reprodutivo em ruminantes. Revta Bras. Agron. 13:299-304.

Quigley III J.D., Smith Z.P. \& Heitmann R.N. 1991. Changes in plasma volatile fatty acids in response to weaning and feed intake in young calves. J. Day. Sci. 74:258-263.

Reece W.O. 2006. Fisiologia dos Animais Domésticos. $12^{\underline{a}}$ ed. Guanabara Koogan, Rio de Janeiro. 856p.

Reis M.C., Costa J.N. \& Peixoto A.P.C. 2007. Efeito da idade e da suplementação oral com o acetato de DL-alfa-tocoferol sobre os níveis séricos de vitamina E sobre o proteinograma de bezerros. Revta Bras. Saúde Prod. Anim. 8:152-161.
Ribeiro T.R., Pereira J.C., Leão M.I., Oliveira M.V.M., Queiroz A.C., Cecon P.R. \& Melo R.C.A. 2001. Tamanho de órgãos e vísceras de bezerros holandeses, para produção de vitelos recebendo dietas com diferentes níveis de concentrado. Revta Bras. Zootec. 30:2163-2168.

Rocha E.0. 1997. Estudo do desaleitamento precoce, exigências nutricionais e características produtivas de bovinos de origem leiteira, para corte. Tese de Doutorado em Zootecnia, Universidade Federal Viçosa, Viçosa, MG. 151p.

Shingu H., Hayashi H., Touno E., Oshibe A., Kushibiki S., Oda S., Katoh K. \& Obara Y. 2007. Characteristics of developmental changes in the kinetics of glucose and urea in Japanese Black calves: comparison with Holstein Calves. J. Anim. Sci. 85:2910-2915.

Silper B.F., Lana A.M.Q., Carvalho A.U., Ferreira C.S., Franzoni A.P.S., Lima J.A., Saturnino H.M., Reis R.B. \& Coelho S.G. 2014. Effects of milk replacer feeding strategies on performance, ruminal development, and metabolism of dairy calves. J. Dairy Sci. 97:1016-1025.

Soberon F., Raffeenato E., Everett R.W. \& Van Amburgh M.E. 2012. Preweaning milk replacer intake and effects on long-termproductivity of dairy calves. J. Dairy Sci. 95:783-793.

Solis J.C., Byers F.M., Schelling G.T., Long C.R. \& Greene L.W. 1988. Maintenance requirements and energetic efficiency of cows of different breed types. J. Dairy Sci. 66:764-773.

Stamey J.A., Janovick Guretzky N.A. \& Drackley J.K. 2005. Influence of starter protein content on growth of dairy calves in an enhanced early nutrition program. J. Dairy Sci. 88(Suppl.1):254. (Abstract)

Sweeney B.C., Rushen J., Weary D.M. \& De Passillé A.M. 2010. Duration of weaning, starter intake, and weight gain of dairy calves fed large amounts of milk. J. Dairy Sci. 93:148-152.

Terré M., Devant M. \& Bach A. 2006. Performance and nitrogen metabolism of calves fed conventionally or following an enhanced-growth feeding program during the preweaning period. Livst. Sci. 105:109-119.

Thomas T.J., Weary D.M. \& Appleby M.C. 2001.Newborn and 5-week-old calves vocalise in response to milk deprivation. Appl. Anim. Behav. Sci. 74:165-173.

Van Amburgh M. \& Drackley J. 2005. Current perspectives on the energy and protein requirements of the pre-weaned calf, p.67-82. In: Garnsworthy P.C. (Ed.), Calf and Heifer Rearing: principles of rearing the modern dairy heifer from calf to calving. Nottingham University Press, Nottingham.

Velayudhan B.T., Daniels K.M., Horrel D.P., Hill S.R., McGilliard M.L., Corl B.A., Jiang H. \& Akers R.M. 2008. Developmental histology, segmental expression, and nutritional regulation of somatotropic axis genes in small intestine of preweaned dairy heifers. J. Dairy Sci. 91:3343-3352. 